\title{
PERAN MUHAKAM DALAM ADAT PERKAWINAN SEBAGAIREPRESENTASI ADAB DAN ETIKA MELAYU SAMBAS
}

\author{
Ahadi Sulissusiawan \\ FKIP Universitas Tanjungpura \\ email: ahadi.sulissusiawan@yahoo.com
}

\begin{abstract}
Abstrak
Penelitian ini bertujuan mendeskripsikan peran Muhakam sebagai representasi adab dan etika dalam adat perkawinan Melayu Sambas. Penelitian ini menggunakan kaidah analisis kualitatif.Data penelitian adalah ucapan (verbal), gerak-gerik (nonverbal), dan pakaian yang digunakan Muhakam ketika memberikan sambutan (alu-aluan) dan nasihat perkawinan. Hasil penelitian menunjukkan bahwa ucapan Muhakam menggambarkan hati yang ikhlas, penuh kasih sayang, dan belas kasihan.Muhakam memperlihatkan strategi ikhlas, merendah diri, dan meminta maaf sebagai representasi adab dan etika Melayu. Adab dan etika Muhakam dalam acara majelis adat perkawinan Melayu ditunjukkan dengan sikap dan perilaku yang dapat menumbuhkan simpati dan respon yang baik dari masyarakat. Kebijaksanaan dan kesantunan dalam berperilaku ditunjukkan oleh Muhakam dengan senyum, bertegur sapa, berjabat tangan, dan adab berpakaian. Peran penting tersebut menjadikan seorang Muhakam dianggap sebagai sosok yang dapat menjaga marwah keluarga dan masyarakat.
\end{abstract}

Kata kunci: Muhakam, pemantun, adab dan etika Melayu, adat perkawinan

\section{A MUHAKAM'S ROLES IN THE WEDDING TRADITION AS A REPRESENTATION OF SAMBAS MALAY MANNERS AND ETHICS}

\begin{abstract}
This study aims to describe the role of a Muhakam as a representation of manners and ethics in the Sambas Malay wedding tradition. This is a qualitative study. The research data are speech (verbal), gestures (nonverbal), and clothinga Muhakam is wearing when giving a speech (alu-aluan) and marital advice. The findings showthat a Muhakam's speech depicts a sincere heart, full of affection and mercy. A Muhakam shows sincere, humble, and apologetic strategies as a representation of Malay manners and ethics. A Muhakam's manners and ethics inthe Malay wedding tradition are shown by the attitude and behavior that can foster sympathy and good responses from the public. The wisdom and politeness in behavior are shown by a Muhakam by smiling, exchanging greetings, shaking hands, and dressing properly. These make a Muhakam considered as someone who can maintain the dignity of the family and society.
\end{abstract}

Keywords: Muhakam, quatrain reciter, Malay manners and ethics, wedding tradition

\section{PENDAHULUAN}

Muhakam diandaikan berasal dari kata Arab hakam yang berarti 'mediator' (Jones, 2007:102). Dalam masyarakat Melayu Sambas Muhakam ditakrifkan seba- gai juru bicara atau wakil keluarga atau mediator untuk menyampaikan maksud dan niat keluarga yang diwakilinya dalam adat perkawinan. 
Fungsi Muhakam sebagai wakil keluarga dalam adat perkawinan Melayu harus memiliki kemampuan dan kebijaksanaan ketika berbicara. Muhakam harus dapat memegang siasat dan strategi konteks dengan memperhatikan siadiba (siapa, di mana, dan bagaimana) semestinya alualuan itu disampaikan. Muhakam harus melihat siapa yang menyelenggarakan acara, di mana tempatnya, dan bagaimana menyampaikan alu-aluannya.

Dalam masyarakat Melayu Sambas Muhakam mesti seorang tokoh dan tetua yang dihormati. Biasanya seorang Muhakam itu kepala kampung, tokoh agama, tokoh adat, tokoh politik, tokoh masyarakat, dan orang yang paling dituakan dalam keluarga. Oleh karena itu, Muhakam memainkan peranan penting dan utama dalam adat perkawinan Melayu Sambas.

Muhakam menjalankan fungsinya sebagai juru bicara dan wakil keluarga untuk menyampaikan segala maksud pihak keluarga yang diwakilinya. Fungsi yang teramat istimewa ini menjadikan seorang Muhakam sebagai sosok yang dianggap dapat menjaga muruah keluarga dan kampung.

Kebijaksanaan dan kesantunan adab bicara Muhakam dalam adat perkawinan Melayu Sambas menggunakan strategi kesantunan yang lazim diamalkan oleh orang-orang Melayu Nusantara. Selain mengucapkan alu-aluan dan ujaran-ujaran yang baik dan menyenangkan orang lain, para Muhakam menjadikan Islam sebagai identitas adab Melayu Sambas dalam menampilkan kebijaksanaan dan kesantunan beralu-aluan.

Kebijaksanaan dan kesantunan adab dan budi bicara Muhakam dalam adat perkawinan Melayu Sambas membuktikan betapa santun dan bijak perkataan orang Melayu. Identitas Islam sebagai ciri-ciri orang Melayu melekat dalam setiap perkataan Muhakam dalam majelis adat perkawinan Melayu Sambas.
Hal ini tidaklah mengherankan karena Melayu dan Islam ibarat jasad dan roh manusia yang telah bersatu padu dalam diri seorang Muhakam (Selat dan Borhan, 2007:34).

Bahasa Muhakam dalam adat perkawinan merupakan perwujudan adab dan akal budi Melayu di Sambas. Budi menghiasi kehidupan orang Melayu sejak lama. Melalui pengalaman dan penyesuaian dengan alam sekitar budi Melayu terangkum dalam satu keseluruhan kehidupan mereka. Oleh karena itu, budi bahasa amat dipandang tinggi dan dihormati.

Hal ini selaras dengan ungkapkan bahwa rupa dan paras jiwa orang Melayu berbentuk budi. Artinya, budi merupakan struktur batiniah Melayu yang terpancar dari satu hikmah yang tertinggi (Tuhan). Bahkan, Selat dan Borhan (2007) menyatakan bahwa budiman dalam masyarakat Melayu sebagai berhati mulia, berakal, bijaksana, beradat, beradab, tahu membalas budi, cukup ajar, dan sebagainya.

Adab dalam kehidupan orang Melayu dapat dilihat dalam hubungannya dengan Tuhan, ibu bapak, isteri, bekas isteri, pemimpin, guru, jiran, musuh, dan juga rekan. Semua perlakuan-perlakuan yang dikatakan beradab dalam kehidupan orang-orang Melayu adalah selaras dengan ajaran Islam (Ahmad, 1997:27-30).

Tidak mengherankan kebijaksanaan dan kesantunan adab Muhakam dalam adat perkawinan Melayu Sambas memperlihatkan adab dan budi seorang Melayu sejati, yaitu Melayu yang berfaksikan Islam sebagai teras dalam berbicara dan berperangai. Hal ini ini juga sejalan dengan kajian empiris yang dilakukan oleh Rashid (2007) mengenai kesantunan orang Melayu di Semenanjung Malaysia dalam majelis pertunangan.

Dalam konteks adat perkawinan Melayu Sambas seorang Muhakam harus cakap berbicara di hadapan masyarakat dan bijak dalam bertutur kata. Oleh karena itu, Muhakam merupakan representasi 
adab Melayu dalam adat perkawinan di Sambas. Hal ini dapat dilihat dari tuturan dan perangai Muhakam ketika dalam majelis adat perkawinan. Dengan demikian, fokus tulisan ini membahas Muhakam dengan melihat adab bicara dan adab perangai ketika melaksanakan tugas sebagai mediator perkawinan.

Tulisan ini diharapkan dapat mengungkap kesantunan Muhakam sebagai manusia budiman, seperti sikap ikhlas, merendah diri, dan meminta maaf dalam majelis adat perkawinan. Selanjutnya, dikaji juga ungkapan rabbani yang dituturkan Muhakam sebagai representasi kesantunan adab, seperti ucapan salam, bismillah, selawat, dan insya-Allah. Selain itu, dideskripsikan juga kesantunan adab perangai (bukan bicara) Muhakam, seperti senyum, bersalaman, berpakaian, dan duduk dalam adat perkawinan Melayu Sambas.

\section{METODE}

Penelitian ini menggunakan kaidah analisis kualitatif (Alwasilah, 2008). Menurut Denzin dan Lincoln (2009:2) penelitian kualitatif merupakan fokus perhatian dengan beragam metode dan model kerja yang mencakup pendekatan interpretatif dan naturalistik terhadap subjek kajiannnya. Hal ini berarti bahwa para peneliti kualitatif mempelajari bendabenda di dalam konteks alaminya, yang berupaya untuk memahami atau menafsirkan fenomena dilihat dari sisi makna yang dilekatkan manusia kepadanya. Hal senada juga dikemukakan Sugiyono (2011:7-8) bahwa metode penelitian kualitatif dinamakan metode postpositivistik karena berlandaskan pada filsafat postpositivisme. Metode ini juga disebut sebagai metode artistik karena proses penelitian lebih bersifat seni (kurang terpola) dan disebut sebagai metode interpretatif karena hasil penelitian lebih berkenaan dengan interpretasi terhadap data yang ditemukan di lapangan.
Data penelitian ini adalah ujaran yang dituturkan oleh para Muhakam mempelai lelaki dan perempuan dalam adat perkawinan Melayu di Sambas. Data utama yang dianalisis adalah ucapan Muhakam ketika memberikan sambutan (alu-aluan) dan nasihat perkawinan. Selain itu, gerakgerik nonverbal dan pakaian yang digunakan Muhakam sebagai representasi perangai menjadi data untuk menganalisis kesantunan adab Melayu masyarakat Sambas dalam adat perkawinan.

Analisis kualitatif dalam penelitian ini menerapkan empat metode analisis yang paling penting, yakni observasi, analisis teks dan dokumen, wawancara, dan transkripsi (Silverman 1993 dalam Alwasilah, 2008:157). Partisipasi observasi dalam penelitian ini dilakukan di Desa Sungai Kelambu dan Tebas Sungai, Kecamatan Tebas, Kabupaten Sambas. Kegiatan observasi partisipasi ini merekam secara keseluruhan ujaran Muhakam dengan kamera digital, handycame, dan MP3 recorder $2 G B$ yang dikenal dengan sebutan Sony IC Recorder.

\section{HASIL DAN PEMBAHASAN \\ Representasi Adab Kesantunan Manusia Budiman}

Kategori ini merupakan simbol ucapan Muhakam dalam menggambarkan hati yang mengandung niat ikhlas yang dipenuhi nilai-nilai kasih sayang dan belas kasihan (Rashid, 2007:50). Simbol kebijaksanaan dan kesantunan adab $\mathrm{Mu}-$ hakam dalam kategori ini memperlihatkan cara Muhakam dalam menjalankan strategi ikhlas, memudahkan, merendah diri, dan meminta maaf. Adab ini berhubungan rapat dengan akhlak Melayu. Jika perlakuan seseorang itu berbudi bahasa, halus bicara, tingkah laku atau berbudi pekerti mulia maka dia akan dikatakan sebagai beradab. Sebaliknya, jika seseorang mempunyai perlakuan dan tutur kata yang kasar maka dia akan dikatakan biadab. Adab dalam kehidup-

Peran Muhakam dalam Adat Perkawinan sebagai Representasi Adab dan Etika Melayu Sambas 
an orang Melayu dapat dilihat dalam hubungannya dengan Allah Tuhan Yang Mahakuasa, ibu bapak, isteri, bekas isteri, pemimpin, dengan guru, dengan jiran, musuh, dan juga rekan. Semua perlakuanperlakuan yang dikatakan beradab dalam kehidupan orang-orang Melayu adalah selaras dengan ajaran Islam (Ahmad, 1997:27-30). Berikut ini dapatan kajian semasa membuat penelitian terhadap Muhakam dalam majelis adat perkawinan Melayu Sambas yang menunjukkan adab manusia budiman.

\section{Berikhlas sebagai Representasi Kesantu- nan Adab dan Etika}

Strategi ini melihat ujaran-ujaran Muhakam yang mengandung maksud yang baik dan suci semata-mata karena Allah. Penanda kebijaksanaan dan kesantunan dalam strategi ini ialah perkataan "ikhlas" atau ungkapan-ungkapan yang membawa makna mempunyai niat yang suci dan baik (Rashid, 2007:50). Strategi ini dilakukan sesuai dengan firman Allah dalam surah An-Nisa ayat 146 yang berbunyi "Kecuali orang-orang yang tobat dan mengadakan perbaikan dan berpegang teguh pada (agama) Allah dan tulus ikhlas (mengerjakan) agama mereka karena Allah. Maka mereka itu adalah bersamasama orang yang beriman dan kelak Allah akan memberikan kepada orang-orang yang beriman pahala yang besar."

Kebijaksanaan dan keikhlasan Muhakam dalam majelis adat perkawinan Melayu Sambas dapat dilihat melalui ujaran yang diucapkannya. Semasa dalam majelis antarbarang (pinang) Muhakam lelaki mengucapkan alu-aluan yang mengandung perkataan baik dan suci karena Allah. Perhatikan kutipan berikut.

“...Alhamdulillah kita panjatkan puji dan syukur kehadirat Allah Swt. bahwa pada malam hari ini kita telah diberikan rahmat, yaitu antara masyarakat yang ada di Desa Tebas Sungai ini. Dengan kami yang datang dari
Ketapang, alhamdulilah kita disatukan dalam tali silaturahmi, amin, amin ya rabbal alamin." (Muslimin, Adat Hntar (Barang) Pinang, 30 Juli 2012).

Ucapan Muhakam dalam ungkapanungkapan di atas sesungguhnya membawa makna niat yang suci dan baik untuk mempererat tali silaturahmi. Pihak keluarga lelaki yang datang jauh dari Ketapang bersedia datang ke Desa Tebas Sungai, Sambas untuk mempererat tali silaturahmi agar dapat menyatukan dua keluarga yang tadinya tidak saling mngenal menjadi satu keluarga besar. Keluarga besar yang disatukan oleh perkawinan lelaki dari Ketapang dan perempuan dari Sambas.

Keutamaan silaturahmi ini sangat penting dalam kehidupan masyarakat Melayu Sambas karena merupakan ajaran Islam yang benar-benar mereka amalkan dalam adat perkawinan Melayu Sambas. Hal ini dapat dilihat melalui hadis Nabi Muhammad Saw yang berbunyi "Anas bin Malik radiyallahuanhu, ia berkata Aku pernah mendengar Rasulullah salallahualaihi wasalam bersabda: Barang siapa yang merasa senang bila dimudahkan rezekinya dan dipanjangkan usianya maka hendaklah dia menyambung hubungan kekeluargaan (silaturahmi) (HR Muslim)" (Utsaimin, 2008:209-255). Sesungguhnya ini adalah adab dan etika orang Melayu (Islam) sebagaimana firman Allah yang berbunyi sebagai berikut.

Hai sekalian manusia, bertakwalah kepada Tuhan-mu yang telah menciptakan kamu dari diri yang satu, dan daripadanya Allah menciptakan istrinya; dan daripada keduanya Allah memperkembang biakkan laki-laki dan perempuan yang banyak. Dan bertakwalah kepada Allah yang dengan (mempergunakan) nama-Nya kamu saling meminta satu sama lain, dan (peliharalah) hubungan silaturahmi. Sesungguhnya Allah selalu men- 
jaga dan mengawasi kamu (An-Nisa: ayat 1$)$.

\section{Merendah Diri sebagai Representasi Ke- santunan Adab dan Etika}

Penanda simbolik bagi Muhakam dalam menunjukkan kebijaksanaan dan kesantunan adab merendah diri adalah dengan menggunakan ungkapan-ungkapan yang membawa maksud bahwa $\mathrm{Mu}$ hakam merendah diri dengan mengakui kelemahan atau kekurangan diri, baik kepada Tuhan maupun sesama manusia. Menurut Utsaimin (2008) dalam ajaran Islam merendah diri adalah bertawadu. Artinya, manusia hendaknya tidak meninggikan diri dan tidak merasa tinggi atas orang lain, baik dengan ilmu, nasab, harta, kedudukan, maupun kepemimpinan. Perintah Allah untuk merendah diri diantaranya ada dalam surah Al-Hijr ayat 88 "...Dan berendah dirilah kamu terhadap orang-orang yang beriman." Itulah mengapa seorang Muhakam tidak boleh merasa hebat dan meninggi-ninggikan diri karena orang yang menonjolnonjolkan dirinya kepada orang lain, seperti seekor burung yang melintas di atas cakrawala langit maka ia diperintahkan untuk merendahkan dirinya dan menurunkannya kepada kaum mukminin (Utsaimin, 2008:642). Dengan merendah diri manusia tersisih dari sikap sombong yang merupakan larangan dalam Islam. Contoh perkataan Muhakam yang memperlihatkan merendah diri diantaranya saat Muhakam menyerahkan pengantin lelaki kepada pihak perempuan dalam majelis adat mulang-mulangkan.

Jadi anak kami yang bernama Kussuhardi ini kami serahkan kepada istrinya yang kami serahkan dari sekarang sampai ke berikutnya dari barangkali ada kekurangannya sampai-sampai kelebihannya dan semuanya kami serahkan dari ujung rambut sampai ke ujung kakinya, dari muda sampai ke tuanya, dari sehat sampai ke sakit- nya, dari hidup sampai ke matinya, itulah kami serahkan kepada istrinya, mudahan-mudahannya istrinya dapat melayani anak kami yang barangkali kalau menurut pendidikannya Alhamdulilah anak kami sudah mencapai sarjana juga barangkali dalam pendidikan tidak meragukan tapi dalam membina keluarga barangkali banyak kekurangan-kekurangan dari itulah kerja sama istrinya dapat menjadi keluarga yang sesuai harapan, yaitu keluarga sakinah mawahdah dan warahmah. (Muslimin, Adat Mulang-Mulangkan, 30 Juli 2012).

Perkataan merendah diri Muhakam disampaikan semasa menyerahkan pengantin lelaki kepada pihak orang tua dan keluarga besar perempuan. Muhakam lelaki menyampaikan keadaan pengantin lelaki yang memiliki banyak kekurangan sehingga mohon dimaafkan. Padahal, pengantin lelaki itu seorang sarjana yang bekerja sebagai seorang guru dan memiliki kehormatan yang tinggi dengan pekerjaannya itu. Tidak diragukan pengantin lelaki insya-Allah pasti mampu menghidupi istrinya secara ekonomi dan mengangkat muruah keluarga istrinya dalam masyarakat karena status sosialnya sebagai guru yang memiliki gaji sebagai pegawai negeri sipil (PNS).

\section{Meminta Maaf sebagai Representasi Ke- santunan Adab dan Etika}

Masyarakat Melayu meyakini bahwa meminta maaf dan memaafkan merupakan satu cara menunjukkan kebijaksanaan dan kesantunan adab. Meminta maaf dan memaafkan itu akhlak budiman orang Melayu sebagai bentuk syukur, sedekah, dan menyenangkan orang lain sehingga orang Melayu tidak dianggap atau dicap lancang dan tak beretika. Oleh karena mulianya meminta dan memberi maaf kepada orang lain maka Imam An-Nawawi dalam kitabnya Riyadhus Shalihin membahas satu

Peran Muhakam dalam Adat Perkawinan sebagai Representasi Adab dan Etika Melayu Sambas 
bab khusus tentang keutamaan-keutamaan memberi maaf dan berpaling dari orang yang bodoh (Utsaimin, 2008:743755). Hal ini selaras dengan firman-Nya dalam surah Al-Baqarah berikut.

Al-Baqarah: 263. Perkataan yang baik dan pemberian maaf lebih baik dari sedekah yang diiringi dengan sesuatu yang menyakitkan (perasaan si penerima). Allah Maha Kaya lagi Maha Penyantun.

Mengamalkan maaf dalam alu-aluan menunjukkan kebijaksanaan dan kesantunan adab dalam berbicara. Dengan demikian, Muhakam menunjukkan kebijaksanaan, kearifan, dan kesantunan dalam berkomunikasi. Ungkapan Muhakam yang meminta maaf sebagai bentuk kebijaksanaan dan kesantunan dalam beralualuan diantaranya dapat dilihat melalui contoh berikut.

“...kami mohon maaf sekiranya apa yang kami serahkan ini, tidak sesuai dengan yang diharapkan maka sekali lagi kami mohon maaf yang sedalamdalamnya. Begitu pula, andaikata kami serombongan ini, ada tersalah dan terhilap maka dengan ini kami mohon ampun dan maaf (Pordi Sabli, Adat Antar (Barang) Pinang, 20 November 2011).

“...Alhamdulilah itu merupaka suatu penghargaan dan penghormatan bagi kami. Baiklah dan juga kami mohon maaf yang sedalam-dalamnya barangkali kedatangan kami tidak sesuai dengan harapan dari pihak rumah atau bapak-bapak, pengemuka masyarakat, pengemuka agama yang ada di Desa Tebas Sungai Kecamatan Tebas Kabupaten Sambas yang menyambut kami. (Muslimin, Adat Hantar (Barang) Pinang, 30 Juli 2012).

Meminta maaf dalam sebuah majelis merupakan adab orang Melayu Sambas. Meminta maaf sudah menjadi simbol kesantunan adab Melayu Sambas dalam beralu-aluan karena dalam perspektif agama ada perintah Allah Swt sebagaimana firman-Nya dalam surah An-Nur ayat 22 yang berbunyi “...dan hendaklah mereka memaafkan dan berlapang dada. Apakah kamu tidak ingin bahwa Allah mengampunimu? Dan Allah adalah Maha Pengampun lagi Maha Penyayang."

Sesungguhnya ucapan Muhakam dalam adat perkawinan Melayu Sambas yang mengandung tutur kata yang ikhlas, memudahkan, merendah diri, dan meminta maaf merupakan falsafah Melayu sejati dalam mengungkapkan konsep budi dan adab.

\section{Representasi Ungkapan Rabbani sebagai Kesantunan Adab dan Etika}

Kategori ini menurut Rashid (2007:66) membuktikan bahwa manusia sentiasa mempunyai hubungan dengan Allah. Orang Melayu pasti akan mengamalkan ajaran dan tuntunan agama Islam dalam kehidupannya. Oleh karena itu, Muhakam sebagai manusia biasa yang percaya dan yakin adanya Allah Sang Maha Pencipta Alam Semesta pasti selalu mengucapkan kata-kata yang bersumber dari ajaran Islam, baik Alquran maupun Sunah Rasulullah.

\section{Representasi Mengucapkan Bismillah, Selawat, dan Doa}

Mengucapkan bismillah, selawat, dan doa merupakan kata-kata suci yang ajarkan Allah melalui Rasulullah Muhammad Saw untuk menunjukkan ketakwaan dan keimanan manusia dihadapan Allah Swt. Para Muhakam memperlihatkan akhlaknya dengan mengucapkan bismillah, selawat, dan doa saat memberikan alu-aluan. Hal demikian merupakan kebijaksanaan dan kesantunan adab para Muhakam dalam berbicara dihadapan majelis. Adab majelis yang sedemikian merupakan petunjuk Allah dan Rasulullah kepada umat manusia yang diamalkan para Muhakam. 
Bismillah diucapkan sebelum sesuatu pekerjaan dimulai. Bismillah berarti "Dengan menyebut nama Allah". Bacaan ini bagi orang Islam sangat dianjurkan membacanya saat memulai setiap aktivitas. Dengan demikian, apa yang dikerjakan diniatkan atas nama Allah sehingga mendapatkan restu atas pekerjaan tersebut dari Sang Maha Pencipta. Ajaran akan kebijaksanaan dan kesantunan diajarkan oleh Rasulullah melalui hadisnya. "Rasulullah Saw berkata kepada Umar bin Abi Salamah, "Wahai anak, ucapkanlah bismillah dan makanlah dengan tangan kananmu, dan makanlah dari apa yang ada dihadapanmu." (HR. Bukhari, dalam Utsaimin, 2008). Praktik membaca bismillah diamalkan oleh orang Melayu tidak hanya pada saat hendak makan, tetapi untuk semua aktivitas manusia sebagai wujud cinta, takwa, dan iman kepada Allah (Utsaimin, 2008:1013-1024).

Menurut Jawas (2008:34) selawat merupakan diantara hak Nabi Salallahu alaihi wasallam yang disyariatkan Allah atas umatnya agar mengucapkan selawat dan salam untuk beliau. Allah dan para malaikat-Nya telah berselawat kepada Rasulullah dan Allah memerintahkan kepada para hamba-Nya agar mengucapkan salam. Hal ini seperti yang ditegaskan Allah dalam Al-Quran surah Al-Ahzab (56) yang berbunyi "Sesungguhnya Allah dan malaikat-malaikat-Nya berselawat untuk Nabi. Hai orang-orang yang beriman, berselawatlah kamu untuk Nabi dan ucapkanlah salam penghormatan kepadanya."

Perintah Allah dalam Alquran itu menjadi dasar untuk berselawat kepada Nabi Muhammad Salallahualaihi wasallam. Selain itu, berselawat memiliki faidah mendapatkan pahala dan derajat yang tinggi karena Allah langsung membalas selawat dengan berselawat kepada manusia tersebut. Perintah berselawat tidak saja dianjurkan oleh Allah tetapi juga oleh Nabi Muhammad Saw yang berbunyi: "Barangsiapa yang berselawat kepadaku dengan sekali selawat, niscaya Allah akan berselawat kepadanya sepuluh kali, dihapuskan sepuluh kesalahannya, dan diangkat baginya sepuluh derajat" (Jawas, 2008:34).

Berdoa dalam alu-aluan juga menjadi satu cara para Muhakam dalam menunjukkan kebijaksanaan dan kesantunannya dalam bermajelis. Berdoa juga adab yang paling disenangi Allah agar dilakukan manusia. Hal ini sebagaimana firmanNya dalam surah Al-Mukmin ayat 60 yang berbunyi "Dan Tuhanmu berfirman, 'Berdoalah kepada-Ku, niscaya akan Kuperkenankan bagimu'." Artinya, dengan berdoa sesungguhnya para Muhakam juga beribadah kepada Allah. Hal ini dipertegas dengan hadis Nabi Muhammad Saw yang berbunyi "Doa adalah otaknya ibadah" (Qasimi, 2010:93).

Para Muhakam dalam berbagai majelis memiliki kelaziman menggunakan adab bermajelis dengan mengucapkan bismillah, selawat, dan doa sebagai cara menunjukkan ketakwaan kepada Allah. Selain itu, ucapan sedemikian ini merupakan identitas orang Melayu dalam alu-aluan atau bermajelis yang tidak diamalkan oleh orang yang bukan Melayu di Sambas. Perhatikan contoh berikut.

"Assalamu alaikum warahmatullah hiwabarakatuh bismillahi rohmani rohim, alhamdullilahi robbil alamin, wassolatu wassolamu ala syaidina muhammadin waala alihi wassobihi azmain amma bakdu. Yang terhormat bapak kepala desa, serta perangkatnya Bapak Haji-haji, Bapak. Pembantu penghulu, Bapak. Amil, Bapak pemuka agama bapakbapak-ibu-ibu,sdr, i para hadirin yang berbahagia. Pertama-tama marilah kita panjatkan puji sukur alhamdulillah kehadiran Allah Swt yang telah dan senantiasa memberikan nikmat, rahmat serta hidayahnya kepada kita semua, dimana dengan nikmat dan rahmat kesehatan dan panjang umur,

Peran Muhakam dalam Adat Perkawinan sebagai Representasi Adab dan Etika Melayu Sambas 
maka dapatlah kiranya kita bersamasama dapat hadir pada majelis yang amat berbahagia ini. Kemudain selawat dan salam tertuju kita sampaikan kepada baginda rasul muhammad s.a.w, sebagai iman dan pemimpin kita dimana beliau, kita selalu dalam Islam dan iman..." (Mizan Zainuddin, Adat Antar Cikram, 7 Januari 2012).

Perkataan Muhakam di atas memperlihatkan adab dan etika Melayu Sambas dalam memulai ucapan selalu dengan bismillah, selawat, dan doa kepada Allah. Hal ini merupakan representasi adab Melayu Sambas yang tidak dimiliki oleh orang bukan Melayu dalam setiap ujaran ketika sambutan (alu-aluan). Setiap aktivitas apa pun orang Melayu dianjurkan untuk selalu mengucapkan bismillah dan berdoa kepada Allah. Berselawat bagi orang Melayu Sambas juga sebuah doa yang mesti disampaikan dan diucapkan dalam berbagai kesempatan. Hal ini jelas merupakan perintah Allah dalam surah Al-Ahzab ayat 56 yang berbunyi "Sesungguhnya Allah dan malaikat-malaikat-Nya berselawat untuk Nabi. Hai orang-orang yang beriman, berselawatlah kamu untuk Nabi dan ucapkanlah salam penghormatan kepadanya."

\section{Representasi Mengucapkan Salam}

Ucapan Assalamualaikum merupakan anjuran agama Islam dan sangat berpengaruh terhadap kehidupan orang Melayu. Dengan salam orang Melayu dapat menjalin persaudaraan dan kasih sayang. Orang yang mengucapkan salam berarti saling mendoakan agar mendapat keselamatan, baik di dunia maupun akhirat. Nabi Muhammad Saw bersabda, sebagaimana dalam hadis riwayat Muslim, "Kalian tak akan masuk surga sampai kalian beriman dan saling mencintai. Maukah aku tunjukkan satu amalan bila dilakukan akan membuat kalian saling mencintai? yaitu sebarkanlah salam di- antara kalian" (Utsaimin, 2008). Oleh karena itu, mengucapkan salam merupakan sebab terwujudnya kesatuan hati dan rasa cinta di antara sesama muslim. Itulah sebabnya para Muhakam mengucapkan salam sebelum memulai alu-aluannya.

Salam dalam Islam bukan hanya sekadar kata sapaan sebagaimana umumnya kata sapaan lainnya. Namun, di dalamnya terkandung doa bagi yang melakukannya. Maknanya, mengucapkan salam berarti menunjukkan kebijaksanaan dan kesantunan dalam majelis. Tambahan pula, Muhakam dalam majelis merupakan tamu yang wajib memberikan salam kepada tuan rumah yang didatanginya. Tidak diragukan lagi salam merupakan perintah Tuhan Semesta Alam yang harus dilakukan oleh orang Melayu dalam kehidupan sehari-hari. Hal ini dapat dilihat dalam Alquran Allah Swt berfirman sebagai berikut.

"Maka apabila kamu memasuki rumah-rumah maka hendaklah kamu memberi salam kepada dirimu sendiri. Salam yang ditetapkan oleh Allah, yang diberkati lagi baik." (AnNur:61).

Rata-rata para Muhakam mengucapkan salam dalam setiap ujarannya. Tidak ada Muhakam yang tidak mengucapkan salam. Salah satu contoh Muhakam yang mengucapkan salam adalah seperti berikut.

"Bismilllahirahmanirrahim. Assalamualaikum warahmatullahi wabarakatuh. Alhamdulilah hirabbil alamin assalatuwassallamuala assrafil ambiya iwal mursallin. Robrisorli sodri wa yasirli amri wahlul uqdatan fi lisani yafkahu kauli ammaba'du. Bapak-bapak Haji yang dirahmati Allah, Bapak Kepala UPT Dinas Kecamatan Tebas yang kami hormati, Bapak Haji Mulyadi selaku anggota DPR Kabupaten Sambas yang kami hormati, Bapak-bapak, Ibu-ibu hadirin wal hadirat yang tidak dapat 
kami sebutkan pangkat dan jabatannya satu persatu. Saya lanjutkan di sini saya ditunjuk mewakili pihak Muhakam perempuan...". (Karnain, 30 Juli 2012).

Ucapan salam juga adab simbol orang Melayu Sambas dalam beralu-aluan. Dalam konteks masyarakat lokal tidak mengucapkan salam berarti bukan orang Melayu. Oleh karena itu, salam merupakan kewajiban orang Melayu Sambas yang harus diucapkan pada berbagai acara. Salam adalah kewajiban yang dipahami orang Melayu sebagaimana perintah Allah dalam surah An-Nur ayat 27 yang berbunyi "Hai orang-orang yang beriman janganlah kamu memasuki rumah yang bukan rumahmu, sebelum meminta izin dan memberi salam kepada penghuninya."

\section{Representasi Mengucapkan Insya-Allah}

Insya-Allah adalah ucapan seseorang yang menyertai pernyataan akan berbuat sesuatu pada masa yang akan datang. Bila diterjemahkan dalam bahasa Melayu akan berarti "Jika Allah mengijinkan". Dalam konsep orang Melayu penggunaan insya-Allah biasanya diucapkan semasa membuat janji. Artinya, ketika seseorang mengucapkan hal tersebut berarti menyerahkan segala keputusan di tangan Allah, dan menerima takdir bahwa Allah bertindak tidak sesuai dengan dugaan manusia. Selain itu, ucapan ini juga diamalkan para Muhakam untuk mengindikasikan bahwa keberhasilan hidup yang diraih bukanlah semata karena usaha keras dan kehendak manusia melainkan lebih kepada rida dari Allah. Oleh karena itu, sebagai orang Melayu dalam Al-Quran telah pun tertulis bahwa dilarang mengucapkan suatu hal yang akan dilakukan pada masa depan (berjanji/berharap) tanpa mengucapkan insya-Allah. Penggunaan insya-Allah sesuai dalil Al-Quran dalam surah AlKahfi ayat 23-24 yang berbunyi: "(23) dan jangan sekali-kali kamu mengatakan tentang sesuatu: "Sesungguhnya aku akan mengerjakan ini besok pagi, (24) kecuali (dengan menyebut): “insya-Allah" dan ingatlah kepada Tuhanmu jika kamu lupa dan Katakanlah: "Mudah-mudahan Tuhanku akan memberiku petunjuk kepada yang lebih dekat kebenarannya dari pada ini."

Para Muhakam mengucapkan insyaAllah karena percaya dan meyakini dalam ajaran Islam dilarang untuk memastikan apa yang akan terjadi di masa depan. Oleh karena itu, harus menyandarkannya kepada kehendak Allah. Sebab segala sesuatu hanya bisa terjadi jika dikehendaki oleh Allah Swt. Ucapan insya-Allah ini mencerminkan pengakuan atas kelemahan diri dan ketergantungan kepada belas kasih kepada Allah Swt agar selalu membantu dalam setiap keinginan dan niat yang datang dari diri seorang hamba. Contoh ucapan Muhakam yang mengandung perkataan insya-Allah adalah sebagai berikut.

Hal ini kami lakukan, adalah mengikut adat resam leluhur kita, dan suatu tradisi dari zaman dahulu yang insyaallah terus kita lestarikan hingga sekarang, dan pada dimasa yang akan dating (Pordi Sabri, Adat Hantar Barang, 20 November 2011).

... Jadi dalam hidup pasti ada kerikilkerikil yang akan kita lalui dan akan kita laksanakan kita hadapi dengan tabah dan sabr insyallah kita akan dapat tempat tujuan yang kita yang mawahdah dan warahmah (Mustafa Munzir, Adat Hantar Barang, 20 November 2011).

Masyarakat Melayu Sambas sadar perkataan insya-Allah merupakan simbol wajib yang harus diucapkan oleh orang Melayu. Oleh karena itu, dalam setiap majelis selalu ada kata insya-Allah dalam alu-aluan seorang Muhakam. Muhakam secara sadar perkataan insya-Allah adalah

Peran Muhakam dalam Adat Perkawinan sebagai Representasi Adab dan Etika Melayu Sambas 
perintah Allah yang disampaikan dan diajarkan Nabi Muhammad Saw bagi orang Islam. Hal ini muncul dalam banyak ayat dan surah dalam Alquran sebagai ilmu orang Melayu Sambas.

Di antara perintah itu muncul dalam Alquran dalam bentuk kisah-kisah. Misalnya, kisah saat Nabi Ibrahim menyampaikan perintah Allah untuk menyembelih Nabi Ismail a.s., anak yang saleh ini berkata: "Wahai Ayahku, kerjakanlah apa yang diperintahkan kepadamu. Insya-Allah engkau akan mendapatiku termasuk orang-orang yang bersabar."(Ash-Shaffat ayat 102). Begitu juga ucapan Nabi Musa a.s. saat beliau berjanji kepada Nabi Khidir a.s. untuk patuh kepada semua arahannya sepanjang perjalanan menuntut ilmu. Nabi Musa berkata: "Insya-Allah engkau akan mendapatiku sebagai orang yang bersabar, dan aku tidak akan menentangmu dalam sesuatu urusan pun." (Al-Kahfi ayat 69).

\section{Representasi Mengucapkan Syukur}

Kebijaksanaan dan kesantunan Melayu yang tidak pernah ditinggalkan para Muhakam dalam beralu-aluan adalah selalu mengucapkan syukur kepada Tuhan Yang Maha Kuasa dan Pemurah. Mengucapkan syukur harus dilakukan karena Tuhan telah memberikan kurniaNya kepada manusia. Bersyukur merupakan kewajiban manusia kepada Allah sebagai wujud cinta dan takwa seorang manusia. Dalam bahasanya Qasimi (2010: 595) seorang hamba tidak menjadi orang yang bersyukur kepada Tuhannya kecuali jika menggunakan nikmat-Nya untuk mencintai-Nya. Dalam bahasa Al-Quran surah Al-Baqarah ayat 172 menjadi contoh perintah Allah supaya manusia bersyukur.

2:172. Hai orang-orang yang beriman, makanlah di antara rezeki yang baikbaik yang Kami berikan kepadamu dan bersyukurlah kepada Allah, jika benar-benar hanya kepada-Nya kamu menyembah.
Contoh ucapan syukur yang sering dilakukan oleh para Muhakam dalam majelis perkawinan adalah berujar Alhamdulillah 'segala puji bagi Allah'. Ucapan ini merupakan cara Muhakam dalam mewujudkan syukur kepada Allah dalam beralu-aluan. Sesungguhnya mengucapkan syukur dalam setiap kesempatan merupakan cara yang memang diajarkan Allah kepada manusia seperti yang ada dalam surah Yunus ayat 10 berbunyi “Doa mereka di dalamnya ialah Subhanakallahumma", dan salam penghormatan mereka ialah "Salam". Dan penutup doa mereka ialah Alhamdulillaahi Rabbil 'aalamin."

Dalam konteks perkawinan Melayu Sambas adab dan etika dalam mengucapkan syukur dapat dilihat melalui perkataan Muhakam bernama Astodi yang mewakili pihak perempuan dalam membalas alu-aluan pihak lelaki. Ia berucap sebagai berikut.

"Bismillah hirrahman nir rahim, assalamualaikum wr wrb, Alhamdulillah $3 x$ hirabbil alamin wassala tuwassala asrapilambia iwal mursalin saidina maulana muhammadin waala alihi wasoh bihi azmain. Bapak Kepala Desa Sejiram atau yang mewakili, perangkat-perangkatnya, bapak-bapak haji yang saya hormati baik dari sejiram maupun Sungai Kelambu, tokoh agama, tokoh masyarakat, baik dari sejiram maupun dari Desa Sungai Kelambu, bapakbapak, ibu-ibu, yang tidak dapat saya sebutkan satu persatu nama, pangkat dan jabatannya. Alhamdulilah kita panjatkan syukur kehadirat Allah Swt. Yang mana pada hari ini adalah acara antar barang-barang meski sudah kita saksikan bersama disini..."

Perkataaan Muhakam yang tidak melupakan untuk selalu mengucap alhamdulillahirabilalamin merupakan simbolisme dalam bersyukur orang Melayu Sambas kepada sang Maha Pencipta Alam Se- 
mesta. Hal itu merupakan wujud ingat dan bersyukur kepada Allah atas segala nikmat yang telah diberikan-Nya kepada manusia. Hal ini dipertegas dalam firman Allah dalam surah Al-Baqarah ayat 152 yang berbunyi "Karena itu, ingatlah kamu kepada-Ku niscaya Aku ingat (pula) kepadamu, dan bersyukurlah kepada$\mathrm{Ku}$, dan janganlah kamu mengingkari (nikmat)-Ku."

\section{Representasi Bertawakal}

Tawakal secara bahasa berarti "mewakilkan" atau "menyerahkan". Dalam Islam, tawakal berarti berserah diri sepenuhnya kepada Allah Swt dalam menghadapi berbagai masalah atau menunggu hasil suatu ikhtiar. Tawakal juga berserah diri kepada-Nya dalam menantikan akibat suatu keadaan (Utsaimin, 2008:457-487). Tawakal merupakan perintah Allah Swt dalam surah Al-Anfaal ayat 49 dan 61 “... Barangsiapa yang tawakal kepada Allah maka sesungguhnya Allah Maha Perkasa lagi Mahabijaksana" (8:49). “...Dan bertawakallah kepada Allah. Sesungguhnya Dialah Yang Maha Mendengar lagi Maha Mengetahui" (8:61). Bahkan, rezeki orang yang bertawakal kepada Allah akan dicukupkan. Hal ini sebagaimana firman-Nya dalam surah At-Thalaq ayat 3 "Barangsiapa yang bertawakal kepada Allah niscaya Allah akan mencukupkan (keperluan) nya. Sesungguhnya Allah melaksanakan urusan (yang dikehendaki)-Nya. Sesungguhnya Allah telah mengadakan ketentuan bagi tiap-tiap sesuatu". Hal ini selaras pula dengan Hadis Rasulullah Saw "Sekiranya kalian benar-benar bertawakal kepada Allah Swt dengan tawakal yang sebenar-benarnya, sungguh kalian akan diberi rizki (oleh Allah Swt), sebagaimana seekor burung diberi rizki; kemanapun ia pergi pada pagi hari dalam keadaan lapar, dan pulang di sore hari dalam keadaan kenyang (HR. Ahmad, Tirmidzi, dan Ibnu Majah, dalam Utsaimin, 2008:457-487).
Tawakal dilakukan setelah berusaha atau menyertai ikhtiar dan doa. Pada zaman Rasulullah Saw dikisahkan tentang bagaimana seharusnya seorang manusia bertawakal dalam hidup. Beliau bersabda “Dari Anas bin Malik ra, ada seseorang berkata kepada Rasulullah Saw 'Wahai Rasulullah Saw aku mengikatnya lalu bertawakal atau aku melepaskannya lalu bertawakal?' Rasulullah Saw menjawab, 'Ikat lalu bertawakallah" (HR. Tirmidzi, dalam Qasimi, 2010:640).

Kebijaksanaan dan kesantunan para Muhakam dalam bermajelis juga memperlihatkan alu-aluan yang mengandung ketawakalan kepada Allah Swt. Para Muhakam tentu meyakini bahwa tawakal adalah sikap mental yang muncul dari keyakinan yang bulat kepada Allah Swt sebagaimana ikrar seorang Muslim dalam setiap salatnya saat membaca Al-Fatihah: "Iyyaka na'budi waiyyaka nasta'in", 'hanya kepada-Mu kami menyembah dan hanya kepada-Mu kami memohon pertolongan.' Muhakam biasanya mengingatkan pasangan pengantin untuk bertawakal kepada Allah jika ada masalah yang dihadapi oleh pasangan yang baru menikah. Jangan mudah menceritakan rahasia dan masalah kepada orang lain. Karena hidup sudah menjadi takdir Allah yang harus disyukuri dan dihadapi dengan kesabaran. Cukup kedua pasangan menjadikan Allah saja tempat mengadu dan bertawakal dalam menghadapi hidup dan jangan mencari orang lain untuk dimintai pertolongan dengan mencerita-ceritakan masalah hidup dan rumah tangga sebagai pasangan suami-istri. Dalam bahasa agama "Bersandarlah kamu kepada Allah dalam segala urusanmu, baik dalam urusan yang kecil maupun besar" (Utsaimin, 2008:462). Perhatikan nasihat Muhakam saat acara mulang-mulangkan berikut.

“...Rahasia hidup berumah tangga jangan dibicarekan ke orang lain. Jadi sudah nikah sudah menjadi kalian itu sudah menjadi jodoh dari Allah

Peran Muhakam dalam Adat Perkawinan sebagai Representasi Adab dan Etika Melayu Sambas 
Swt Kita harus tabah dan sabar dan jangan lagi menyesal dan itu pasti kita ketemukan. Jadi masalah rumah tangga jangan diceritakan kepada orang lain seperti kemiri kulitnya keras bisa memelihara isinya di dalam. Jangan dibicarekan kepada orang lain karena itu sudah jadi suami kita, sudah jadi istri kita, ibarat pribahasa seperti pribahasa ditepuk air didulang terpercik ke muka sendiri..." (Mustafa Munzir, Mulang-mulangkan, 20 November 2011).

Bertawakal dalam petikan ucapan di atas berkaitan dengan nasihat muhakam bahwa pernikahan yang telah terjadi merupakan jodoh dan kehendak Allah semata. Dalam mengarungi bahtera perkawinan banyak masalah yang akan dihadapi. Oleh karena itu, mesti bersabar dan bertawakal kepada Allah dengan tidak menyesali takdir yang telah ditetapkan-Nya. Hal ini selaras dengan hujah Imam Al-Ghazali yang mengartikan tawakal dengan Menyandarkan karunia kepada Allah Swt bukan kepada yang lain dan kepada makanan karena mungkin semua itu menjadikan tanganmu jauh, rusak semua gerakmu, dan mungkin Allah menimpakan kepada engkau orang lain yang mengalahkanmu demi makanan (lihat Qasimi, 2010:638).

\section{Representasi Kesantunan Adab dan Etika Perangai (Bukan Bicara)}

Kebijaksanaan dan kesantunan adab Muhakan dalam acara majelis adat perkawinan Melayu ditunjukkan dengan sikap dan perangai yang baik. Perangai yang menyenangkan orang lain dan merebut hati orang yang dihadapinya agar mendapatkan perlakuan dan respon yang baik. Kebijaksanaan dan kesantunan dalam berperilaku itu ditunjukkan oleh Muhakam dengan senyum, bersalaman, duduk, dan berpakaian.

\section{Senyum sebagai Adab dan Etika}

Nabi Muhammad Saw mensunahkan dan memerintahkan umatnya agar menghiasi diri dengan senyum sebagai salah satu bentuk akhlak mulia. Beliau menjadikan senyuman sebagai lahan berlomba dalam kebaikan. Sabda Rasulullah Saw berbunyi: "Senyummu kepada saudaramu adalah sedekah" (HR. Tirmidzi, dalam Utsaimin, 2008). Oleh karena itu, senyuman ialah ibarat sebuah sihir yang dapat menyenangkan dan membahagiakan orang lain.

Senyuman adalah bukti cinta kasih dan persaudaraan sesama manusia. Senyuman akan melahirkan kehidupan yang indah, mampu melembutkan wajah, dan sanggup menaklukan hati. Bila direnungkan tersenyum merupakan suatu perangai yang punya nilai tinggi untuk menghormati orang lain. Oleh karena itulah, para Muhakam pasti tersenyum ketika berbicara dalam majelis adat perkawinan demi menaklukkan hati dan menghormati orang dalam majelis terhormat itu. Rata-rata para Muhakam yang diselidiki pasti senyum dan tertawa saat berinteraksi dan berkomunikasi dengan anggota majelis yang hadir dalam adat perkawinan Melayu di Sambas.

Allah Swt pun menyenangi orang yang tersenyum. Di dalam Al-Quran surah An-Naml ayat 19 Allah merekam kisah Nabi Sulaiman as, yang tersenyum kepada seekor binatang saat Sulaiman as berkata kepada seekor semut. Ayat ini menjadi iktibar kepada manusia bahwa dengan seekor semut saja seorang manusia tersenyum apatah lagi dengan sesama manusia. Oleh karena itu, manusia mestilah mengamalkan senyum sebagai perangai yang bijak dan santun.

\section{Bersalaman sebagai Adab dan Etika}

Bersalaman boleh dikatakan sebagai satu bentuk penghormatan atau tanda kemesraan antarindividu ketika bertemu. Dengan bersalaman akan menimbulkan 
kemesraan dan kasih sayang dengan sesama. Bersalaman juga menyebabkan perkenalan dan persahabatan bagi yang baru bertemu. Bahkan, bersalaman merupakan sunah Nabi Nuhammad Saw yang berbuah pahala sebagaimana sabda Rasulullah "Tidaklah dua orang muslim yang bertemu lalu bersalaman kecuali akan diampuni dosa keduanya sebelum mereka berpisah" (HR Abu Daud, dalam Utsaimin, 2008).

Hal ini pula menjadi adab bagi Muhakam dan rombongan dalam majelis adat perkawinan Melayu di Sambas. Muhakam pihak lelaki sebagai kepala rombongan akan menjadi orang yang paling depan memimpin bersalaman dengan tuan rumah. Begitu juga dengan Muhakam pihak perempuan akan menyambut dengan bersalaman sebagai tanda kegembiraan, kemesraan, dan persaudaraan se-Muslim. Hal ini membuktikan bahwa kebijaksanaan dan kesantunan berperilaku Muhakam dengan mengamalkan bersalaman akan memperkuat dan mengukuhkan kemesraan dalam keridaan Allah.

\section{Duduk sebagai Adab dan Etika}

Posisi duduk juga satu adab dan etika yang memperlihatkan kebijaksanaan dan kesantunan Muhakam beserta rombongan. Pertama posisi duduk muhakam (secara khusus), yaitu di depan rombongan dari pihak pengantin perempuan, begitu juga Muhakam pihak pengantin laki-laki. Posisi duduk rombongan perempuan dan lelaki dipisahkan pada ruang yang berbeda. Perempuan duduk di ruang tamu rumah, sedangkan lelaki duduk di majelis tarup yang dibangun di depan rumah.

Duduk bersila-sila, baik lelaki maupun perempuan dalam posisi saling berhadap-hadapan. Di dalam majelis tarup posisi duduk lelaki membentuk dua baris lurus saling berhadap-hadapan. Posisi duduk yang saling berhadap-hadapan ini merupakan majelis tertib dan sopan yang diajarkan Allah kepada orang Melayu.
Hal ini sebagaimana Allah kisahkan posisi duduk para penghuni surga yang tertib dan sopan di dalam Al-Quran berdasarkan surah Al-Hijr ayat 47, Ash-Shaffat ayat 44, Ad-Dhukhan ayat 53, dan Al-Waqiah ayat 16 berikut. "Dan kami lenyapkan segala rasa dendam yang berada di dalam hati mereka, sedang mereka merasa bersaudara duduk berhadap-hadapan di atas dipan-dipan."(Al-Hijr: 47); "Di atas takhta-takhta kebesaran berhadaphadapan (Ash-Shaffat: 44); "Mereka memakai sutera yang halus dan sutera yang tebal, (duduk) berhadap-hadapan" (AdDhukhan: 53); dan "Seraya bertelekan di atasnya berhadap-hadapan." (Al-Waqiah: 16). Filosofi duduk berhadap-hadapan membuat hati mereka bersih dari kebencian dan hasad karena senantiasa menyucikan Allah serta saling menyayangi dan bersaudara. Hal ini pula yang melatari duduk berhadap-hadapan bagi majelis adat perkawinan Melayu di Sambas.

\section{Pakaian Muhakam sebagai Adab dan Etika}

Menurut Ismail (1991:65) dalam masyarakat Melayu berpakaian merupakan unsur tradisi adat yang simbolis. Hal ini biasanya dihubungkan dengan adat tradisi istana yang membawa simbol kebesaran memakai pakaian kerajaan selengkapnya.

Cara berpakaian Muhakam merupakan representasi simbolis orang Melayu Sambas. Muhakam menjadikan pakaian menjadi memiliki makna tersendiri saat dipakai. Pakaian yang simbolis itu mewujudkan falsafah keindahan Melayu (Arba'iyah bt Ab Aziz. 2010:535-537). Dalam bahasanya Ismail (1991:85-86) fungsi simbolis adalah gabungan antara makna fungsi dan simbol. Pakaian mulai memberi arti sosial; melibatkan nilai estetis instrinsik. Dalam konteks ini, tradisi menghias diri bukan saja berarti keseronokan peribadi, melainkan telah didasari oleh keperluan spiritual. Dalam

Peran Muhakam dalam Adat Perkawinan sebagai Representasi Adab dan Etika Melayu Sambas 
masyarakat purba yang animisme pakaian dan perhiasan adalah satu dari simbol yang dihormati. Ketua adat dihormati melalui simbol-simbol pakaian, seperti memakai topi bulu burung dan kain adat. Dalam masyarakat tradisi agung, fungsi simbolis dapat dilihat melalui penggunaan warna pakaian (kuning raja) yang membedakan dengan rakyat biasa.

Cara berpakaian Muhakam yang terbabit dalam adat perkawinan Melayu Sambas itu menggunakan tiga jenis simbol berpakaian. Pertama, ada Muhakam yang menggunakan stelan pakaian Melayu dan berkopiah (teluk belanga). Pakaian Melayu ini merupakan kain teluk belanga yang dilengkapi dengan kain cual. Bagi sesetengah Muhakam pakaian teluk belanga merupakan warisan adat Melayu yang harus dipakai oleh Muhakam dalam adat perkawinan. Bahkan, menurut Mustafa Munzir seorang Muhakam dari Kampung Sungai Kelambu cara memakai kain cual pun ada etikanya tersendiri. Apabila orang umum kepala kain lazimnya diletakkan di belakang. Apabila dia seorang penyambut tamu kepala kain diletakkan di depan. Jikalau ia seorang berkedudukan penting di pemerintahan maka kepala kain di kanan dan jika seorang pengantin diletakkan kepala kain di sebelah kiri. Akan tetapi, ada juga Muhakam yang tidak mempersoalkan cara memakai kain cual tersebut.

Simbolis kedua, seorang Muhakam ada yang menggunakan setelan pakaian muslim berwarna putih, bercelana kain hitam panjang, dilengkapi pula dengan stelan jas hitam dan berkopiah. Simbolis ketiga, ada Muhakam yang menggunakan pakaian muslim dengan corak warna apa saja, dilengkai stelan celana kain hitam panjang, dan berkopiah. Apabila Muhakam itu ialah seorang haji maka ia akan menggunakan kopiah haji berwarna putih dan dilengkapi dengan sorban dan sal kelengkapan identitasnya sebagai seorang haji.

\section{SIMPULAN}

Dapat disarikan bahwa segala yang diucapkan oleh Muhakam dalam majelis adat perkawinan merupakan strategi kesantunan dan adab orang Melayu Sambas yang disimbolismekan pada sosok $\mathrm{Mu}$ hakam. Muhakam memainkan peranan penting dan utama dalam adat perkawinan Melayu Sambas. Muhakam menjalankan fungsinya sebagai juru bicara dan wakil keluarga untuk menyampaikan segala maksud pihak keluarga yang diwakilinya. Fungsi yang teramat istimewa ini menjadikan seorang Muhakam sebagai sosok yang dianggap dapat menjaga muruah keluarga dan kampung.

Muhakam menjadi simbolisme adab dan etika Melayu dalam adat perkawinan Melayu Sambas. Ucapan Muhakam dalam beralu-aluan menggambarkan hati yang mengandung niat ikhlas, yang dipenuhi nilai-nilai kasih sayang, dan belas kasihan. Muhakam memperlihatkan strategi ikhlas, merendah diri, dan meminta maaf. Adab ini berhubungan rapat dengan akhlak Melayu. Selain itu, adab Muhakam dalam acara majelis adat perkawinan Melayu ditunjukkan dengan sikap dan perangai yang baik.

Perangai yang menyenangkan orang lain dan merebut hati orang yang dihadapinya agar mendapatkan perlakuan dan respon yang baik. Kebijaksanaan dan kesantunan dalam berperilaku itu ditunjukkan oleh Muhakam dengan senyum, bersalaman, duduk, dan berpakaian. Simbolisme Muhakam dalam berbicara dan berperangai dapat dilihat dalam majelis antar barang (pinang) dan mulangmulangkan sebagai peringkat-peringkat dalam adat perkawinan Melayu Sambas.

\section{UCAPAN TERIMA KASIH}

Penelitian ini bagian dari subbab sebuah tesis doktoral tahun 2014 di Universiti Malaya, Kuala Lumpur. Untuk itu, ucapan terima kasih kepada para penyelia Prof. Madya Dr. Zahir Ahmad, Prof. Dato' 
Dr. Yaacob Harun, dan Prof. Dato' Zainal Abidin Borhan yang telah memberikan arahan, masukan, dan saran yang baik, logis, dan ilmiah dalam penelitian ini.

\section{DAFTAR PUSTAKA}

Ahmad, Zahir. 1997. “Riwayat Kelantan: Analisis Teks, Interteks dan Konteks". Tesis Doktor Falsafah. Jabatan Pengajian Melayu, Fakulti Sastera dan Sains Sosial. Universiti Malaya.

Alwasilah, A. Chaedar. 2008. Pokoknya Kualitatif. Jakarta: PT Dunia Pustaka Jaya.

Arba'iyah bt Ab Aziz. 2010. "Simbolisme dalam Motif-Motif Songket Melayu Terengganu". Tesis Ph.D di Jabatan Pengajian Melayu, Universiti Malaya.

Denzin, Norman K. dan Yvona S. Lincoln (Ed.). 2009. Handbook of Qualitative Research. Yogyakarta: Pustaka Pelajar.

Denzin, Norman K. dan Yvona S. Lincoln. "Memasuki Bidang Penelitian Kualitatif" Dalam Denzin, Norman K dan Yvonna S. Lincoln (eds), Handbook of Qualitative Research. Yogyakarta: Pustaka Pelajar.

Jawas, Yazid bin Abdul Qadir. 2008. Sifat Shalawat Nabi. Bogor: Media Tarbiyah.

Jones, Russell. 2007. Loan-words in Indonesia and Malay. Leiden: KITLV Press.

Karnain, penelitian lapangan,di Tebas Sungai, Tebas, Sambas. pada tanggal 30 Juli 2012.

Mizan Zainuddin, penelitian lapangan, adat antarcikram di Mensere, Tebas, Sambas. pada 7 tanggal Januari 2012
Musatafa Munzir, penelitian lapangan, adat hantar barang 20 November 2011 di Desa Sungai Kelambu, Tebas, Sambas.

Muslimin, penelitian lapangan, adat hantar barang di Tebas Sungai, Tebas, Sambas. pada tanggal 30 Juli 2012.

Pordi Sabri, penelitian lapangan, adat hantar barang, pada tanggal 20 November 2011 di Desa Sungai Kelambu, Tebas, Sambas.

Qasimi, Jamaluddin. 2010. Buku Putih Ihya 'Ulumuddin Imam Al-Ghazali. Penerjemah Asmuni. Jakarta: Darul Falah.

Rashid, Noriati A.. 2007. Kesantunan Orang Melayu dalam Majlis Pertunangan. Tanjong Malim: Penerbit Universiti Sultan Idris.

Selat, Norazit dan Zainal Abidin Borhan. 2007. "Pantun Budi: Satu Analisis Nilai". dalam Pantun Manifestasi Minda Masyarakat. Kuala Lumpur: Akademi Pengajian Melayu, Universiti Malaya.

Ismail, Siti Zainon. 1991. “Konsep Pakaian Cara Melayu: Satu Kajian Analisis Budaya Benda". Tesis Ph.D di Jabatan Pengajian Melayu, Universiti Malaya.

Sugiyono. 2011. Metode Penelitian Kuantitatif, Kualitatif, dan $R \mathcal{E} D$. Bandung: Alfabeta.

Utsaimin, Muhammad bin Shalih. 2008. Syarah Riyadhus Shalihin Imam AnNawawi. Penerjemah Asmuni. Jakarta: Darul Falah.

Zainal Kling. 1995. "Manusia Melayu, Alam dan Tamadunnya" dalam Hari Sastera, Melaka. 